\title{
Emergency department referrals from a provincial medical call centre: Is it more than just 1-800-go-to-emerg?
}

\author{
Jonathon Nataraj, BSc, MD*; James Stempien, BSc, MD*; Stuart Netherton, PhD, MD*; Mark \\ Yosri Wahba, MD*; Taofiq Olusegun Oyedokun, MBChB, MMed*
}

\begin{abstract}
CLINICIAN'S CAPSULE
What is known about the topic?

Medical call centres are commonly used, but the effectiveness of their referrals is often questioned by emergency department (ED) staff.

What did this study ask?

Are referrals from Saskatchewan's medical call centre (HealthLine) appropriate, and do they overburden the local EDs?

What did this study find?

The majority of callers to HealthLine were not referred to EDs, and approximately half of those referred registered in local EDs.

Why does this study matter to clinicians?

Given the inherent challenges of telephone triage, HealthLine does a reasonable job of referrals and does not overburden EDs.
\end{abstract}

\section{ABSTRACT}

Objective: HealthLine is Saskatchewan's provincial 24-hour health information and support telephone line. A proportion of HealthLine's callers are referred to the emergency department (ED) for further assessment. The purpose of this study was to gain insight into the appropriateness of these referrals and assess whether they increased the burden on an already strained ED system.

Methods: A list of callers referred from HealthLine to Saskatoon EDs from January 1, 2014, to March 31, 2014 was obtained. This list was cross-referenced with Saskatoon Health Region registration data to determine which of those callers had been registered in one of the three Saskatoon EDs within 48 hours of the original call.

Results: During the 90-day time period in question, 707/3,938 $(17.9 \%)$ of callers were referred by HealthLine to the ED. Out of those referred, 601 were identifiable and 358 attended the
ED. Hospital charts were pulled for full data extraction and anaIysis of the 276 who met inclusion criteria. Of those who presented to the ED and met inclusion criteria, $60 \%$ had investigations performed while $66 \%$ received some form of treatment. The overall admission rate for the patient population studied was $12.0 \%$ v. $16 \%$ for non-referred patients. Referred pediatric patients had fewer investigations and treatments with a lower admission rate compared with the adult patients. Conclusion: The Saskatchewan HealthLine is doing an effective job at directing callers both to and away from EDs in Saskatoon and not overburdening our local EDs with unnecessary referrals.

\section{RÉSUMÉ}

Objectif: Le service téléphonique provincial d'information sur la santé et de soutien aux appelants en Saskatchewan, HealthLine (I'équivalent d'Info-Santé), est disponible 24 heures sur 24 , et un certain nombre de ces appelants sont dirigés vers les services des urgences pour évaluation. L'étude avait donc pour buts d'examiner la pertinence des aiguillages et d'évaluer s'ils avaient pour effet de surcharger un système de services des urgences déjà soumis à rude épreuve.

Méthode: Une liste d'appelants dirigés par le service HealthLine vers les SU de Saskatoon, du $1^{\mathrm{er}}$ janvier au 31 mars 2014, a été transmise à l'équipe de recherche. Celle-ci a, par la suite, procédé à des recoupements avec des données d'inscription provenant de la région sanitaire de Saskatoon afin de déterminer lesquels, parmi ces appelants, s'étaient inscrits dans I'un des trois SU de Saskatoon, dans les 48 heures suivant l'appel initial. Résultats: Durant la période à l'étude de 90 jours, 707 appelants sur 3938 (17,9\%) ont été dirigés vers un SU par le service HealthLine. Pour 601 d'entre eux, l'équipe disposait de renseignements identificatoires, et 358 se sont effectivement rendus au SU. II y a eu ensuite extraction de données complètes des dossiers médicaux hospitaliers, dont 276, satisfaisant aux critères de sélection, ont fait l'objet d'analyse. Parmi les appelants qui sont allés au SU et qui répondaient aux

From the *University of Saskatchewan, Saskatchewan Health Authority, Saskatoon, SK.

Correspondence to: Taofiq Olusegun Oyedokun, University of Saskatchewan, Department of Emergency Medicine, Rm 2646, Royal University Hospital, 103 Hospital Drive, Saskatoon, SK S7N 0W8; Email: segunoyedo@yahoo.ca

(C) Canadian Association of Emergency Physicians

CAEP | ACMU
CJEM 2020;22(2):241-244

DOI 10.1017/cem.2019.420
$2020 ; 22(2)$ 
critères de sélection, $60 \%$ ont été soumis à des examens et $66 \%$, à une forme ou à une autre de traitement. Le taux général d'hospitalisation chez ces patients ainsi dirigés s'élevait à $12,0 \%$ contre $16 \%$ chez les autres patients. Quant aux enfants orientés vers le SU, ils ont subi moins d'examens et moins de traitements que les adultes; il en allait de même pour le taux d'hospitalisation qui était moins élevé.
Conclusion: Le service HealthLine en Saskatchewan effectue son travail d'une manière efficace lorsqu'il dirige les malades vers les SU à Saskatoon, et les aiguillages n'ont pas pour effet de surcharger les SU locaux avec des consultations inutiles.

Keywords: Emergency medicine, HealthLine, health services, referral

\section{INTRODUCTION}

It has been estimated that $50 \%$ of after-hours health concerns could be handled over the telephone. ${ }^{1,2}$ Telephone call centres staffed by trained healthcare providers using computer-based support systems have been established to address this issue. Telephone consultations have shown usefulness in providing appropriate emergency department (ED) referrals for poisonings, ${ }^{3}$ pediatric patients, ${ }^{4,5}$ and adult patients. ${ }^{6-8}$ However, telephone referrals have been criticized by receiving physicians 9 and almost half of urgent referrals being identified as non-urgent by ED triage. ${ }^{10}$

In Saskatchewan, the telephone health consultation line is called HealthLine. Saskatchewan residents who have a health concern can call 811 and be directed to the appropriate personnel to render healthcare advice.

The purpose of this study was to gain insight into HealthLine patients who were referred to EDs in Saskatoon and the effectiveness of HealthLine in triaging patients based on the investigations, treatment, and disposition of the ED visit.

\section{METHODS}

This study is a health records review on patients referred by HealthLine to any of the three Saskatoon academic EDs between January 1 and March 31, 2014. In the city of Saskatoon, with a population of 254,569 in 2014, the three EDs had a combined annual census of over 110,000 patient visits. Ethics approval was obtained from the University of Saskatchewan Research Ethics Board. Patients were eligible for inclusion if they called HealthLine during the study period and were subsequently directed to present to an ED. The research team had no measure of the conversation between the patient and HealthLine operator - only the disposition. The referred patients were excluded if they were unable to be identified by a personal health number, instructed to hang up and call 911 immediately, or if they registered in the ED after 48 hours. Other patients arriving by ambulance were not excluded. The 48-hour time limit was to increase the likelihood that the presenting complaint to the ED and the Healthline concern were the same.

A list of personal health numbers was obtained of patients who called HealthLine during the study period and were referred to a Saskatoon ED. This list was then cross-referenced with the Saskatoon Health Region ED registration list from the same time period, limiting the time of registration to within 48 hours of the initial call. These charts were subsequently accessed from health records. Each chart was reviewed to find the corresponding ED visit based on the HealthLine referral date. Patient characteristics (age, gender), ED Canadian Triage and Acuity Scale (CTAS) score, and a binary "yes" or "no" answer as to whether investigations, treatments, and/or admission took place were entered into an encrypted, password-protected spreadsheet. Investigation was defined as any test ordered by the emergency physician, including diagnostic imaging, laboratory tests, or electrocardiogram. Treatment in the ED was defined as any therapeutic intervention provided to the patient, including administration of medication (oral or intravenous), intravenous fluids, and/or any bedside intervention performed by the ED physician. Physical examination and/or vital signs were not included as investigations or treatment. Admission was defined by whether the patient was subsequently admitted to the hospital under a consulting service.

\section{RESULTS}

From January 1, 2014, to March 31, 2014, HealthLine received 5,708 calls, resulting in 7,656 registered patients, as one call can register multiple patients. Based on the initial client navigator assessment, 3,938 
of the calls went to a triage nurse. The remainder received health education or service referrals. Of those 3,938 triaged calls, 707 (17.9\%) HealthLine patients were referred to EDs in Saskatoon.

Of the 707 callers, 106 had no available ED identifying information (personal health numbers) and were therefore excluded from further study, leaving 601 potential patients. Because 243 did not register within the 48-hour timeline, they were also excluded. Of those callers whose personal health number could be found, the number of patients attending the $\mathrm{ED}$ as instructed was 358 . Of these 358 patients, 82 either left against medical advice or left without being seen (LWBS) in the ED or had incomplete charts and were therefore excluded from further analysis. The remaining 276 patients had hospital charts pulled for full data extraction and analysis (Table 1).

During the study period, there were 29,529 total patient visits to the three EDs. The total patients referred from HealthLine equated to $2.4 \%$ of these $\mathrm{ED}$ visits and those who presented equated to $1.3 \%$ of total ED visits. The patient flowchart is shown in supplementary material Appendix Figure 1. Rates of investigation, treatment and admission of both adults, pediatric and all patients referred from HealthLine are shown in supplementary material Appendix Table 1.

\section{DISCUSSION}

The aim of the study was to evaluate the burden of HealthLine referrals to Saskatoon EDs. If all referred patients presented to the ED as instructed, this would have comprised $2.4 \%$ of total ED visits. However, with the reduced compliance following telephone consultation advice found in our study, HealthLine referrals comprised only $1.3 \%$ of the total patient visits to Saskatoon EDs. This would equate to approximately four more patient visits per day spread across the three EDs. We do not deem this to be a large nor inappropriate burden. More importantly, if HealthLine did not exist, there is the potential of an extra 21 patients per day presenting to EDs seeking treatment advice. Greater than $70 \%$ of the time, HealthLine nurses provided instructions for self-home care or directed patients to make an appointment with their primary care provider.

For the referred patients who presented to the ED as instructed, greater than half of the pediatric population

\begin{tabular}{|c|c|}
\hline Demographics & Number (\%) \\
\hline \multicolumn{2}{|l|}{ Sex $x^{*}$} \\
\hline Female & $187(68)$ \\
\hline \multicolumn{2}{|l|}{ Age } \\
\hline \multirow[t]{4}{*}{ Adults (>17 years) } & $178(64.5)$ \\
\hline & Age -41.8 years \\
\hline & $S D- \pm 18.3$ \\
\hline & Range - $18-89$ years \\
\hline \multirow[t]{4}{*}{ Children (<17 years) } & $98(35.5)$ \\
\hline & Age -4.3 years \\
\hline & $\mathrm{SD}- \pm 4.9$ \\
\hline & Range -14 days -17 years \\
\hline \multicolumn{2}{|l|}{ Location of visit } \\
\hline Royal University Hospital & $178(64.5)$ \\
\hline St Paul's Hospital & $83(30.1)$ \\
\hline Saskatoon City Hospital $^{\dagger}$ & $15(5.4)$ \\
\hline \multicolumn{2}{|l|}{ CTAS score $e^{\ddagger}$} \\
\hline 1 & $0(0)$ \\
\hline 2 & $30(10.9)$ \\
\hline 3 & $124(44.9)$ \\
\hline 4 & $77(27.9)$ \\
\hline 5 & $44(15.9)$ \\
\hline \multicolumn{2}{|c|}{ Commonest chief complaints } \\
\hline Abdominal pain & $44(15.9)$ \\
\hline Vomiting and nausea & $28(10.1)$ \\
\hline Cough/congestion & $17(6.2)$ \\
\hline \multicolumn{2}{|c|}{ Commonest discharge diagnoses } \\
\hline Gastroenteritis & $29(10.5)$ \\
\hline Abdominal pain & $21(7.6)$ \\
\hline URTI & $9(3.3)$ \\
\hline Investigation & $166(60)$ \\
\hline Treatment & $188(68)$ \\
\hline Admission & $33(12)$ \\
\hline
\end{tabular}

received an intervention or treatment, whereas almost three quarters of the adult population did so. In the studied population, $8.2 \%$ of pediatric patients were admitted to the hospital, and of the adult population, $14 \%$ were admitted. When compared to the non-HealthLine referred patient population during our study period, the pediatric admission rate was $9.3 \%$, and adult admission rate was $16 \%$. This suggests that the referrals from HealthLine, for the most part, were appropriate. Thus, we believe that, despite the challenges of telephone triage, the Saskatchewan HealthLine system is appropriately referring patients to the EDs for further assessment. 


\section{Limitations}

A major limitation of this study is missing data. There was no personal health number for $15 \%$ of the patients referred to the ED, and $23 \%$ of those who actually presented within 48 hours had LWBS or had incomplete charts. As mentioned, details on the type of investigation or treatment were not collected. Within our study population and period, there was poor compliance with the instructions to present to an ED immediately, as only $50.6 \%$ of patients did so within 48 hours. It is possible that their situation changed or they did not value the advice they received.

Although there can be a stigma regarding patients referred from HealthLine, these patients' complaints should not be disregarded.

Further studies could examine why patients did not present to the ED after being instructed to do so.

\section{CONCLUSIONS}

Clinicians should not be quick to dismiss someone referred by a medical call centre. During the study period, HealthLine directed only $17.9 \%$ of patients to EDs for further evaluation, of which the majority received investigations and/or treatment. These referrals from HealthLine accounted for a small portion $(1.3 \%)$ of total ED volume.

Supplementary material: The supplementary material for this article can be found at https://doi.org/10.1017/cem.2019.420.

Acknowledgements: We would like to thank Roberta Wiest and Karen Dickson for providing the initial data from HealthLine and allowing the research team to directly observe the telephone consultation process. We are also grateful to Aimee Goss from Health Records at Saskatoon Health Region, and to Shari McKay, the research coordinator from the Department of Family Medicine, University of Saskatchewan, for their support throughout the study.

Competing interests: None declared.

\section{REFERENCES}

1. Dale J, Crouch R, Lloyd D. Primary care: nurse-led telephone triage and advice out-of-hours. Nurs Stand 1998; 12(47):41-5.

2. Christensen MB, Olesen F. Out of hours service in Denmark: evaluation five years after reform. BM7 1998;316:1502-6.

3. Jackson BF, McCain JE, Nichols MH, et al. Emergency department poisoning visits in children younger than 6 years: comparing referrals by a regional poison control center to referrals by other sources. Pediatr Emerg Care 2012; 28(12):1343-7.

4. Stewart B, Fairhurst R, Markland J, Marzouk O. Review of calls to NHS Direct related to attendance in the paediatric emergency department. Emerg Med 7 2006;23(12):911-4.

5. Kempe A, Dempsey C, Whitefield J, et al. Appropriateness of urgent referrals by nurses at a hospital-based pediatric call center. Arch Pediatr Adolesc Med 2000;154(4):355.

6. Tariq A, Li L, Byrne M, et al. Medication-related queries received for "after hours GP helpline" - comparison of callers' intentions with GPs' advice. Aust Fam Physician 2016; 45(9):661-7.

7. Conway J, Higgins I, Hullick C, Hewitt J, Dilworth S. Nurse-led ED support for residential aged care facility staff: an evaluation study. Int Emerg Nurs 2015;23(2):190-6.

8. Barber JW, King WD, Monroe KW, Nichols MH. Evaluation of emergency department referrals by telephone triage. Pediatrics 2000;105(4 Pt 1):819-21.

9. Al-Abdullah T, Plint AC, Shaw A, et al. The appropriateness of referrals to a pediatric emergency department via a telephone health line. CFEM 2009;11(2):139-48.

10. Scarfone RJ, Luberti AA, Mistry RD. Children referred to an emergency department by an after-hours call center: complaint-specific analysis. Pediatr Emerg Care 2004;20(8): 507-13 